\title{
sciendo
}

\section{The impact of using emoji in online advertisements on consumer behavior. Case: Banking sector in Lebanon}

\author{
Bassam TARHINI \\ Bucharest University of Economic Studies, Bucharest, Romania \\ bassam.tarhini@liu.edu.lb \\ Sandy SAIKALY \\ Lebanese International University, Sidon, Lebanon \\ sandy_saikaly@hotmail.com
}

\begin{abstract}
Communication is an essential element in life. It is key to understanding each other, forming relationships, and sharing knowledge, information and ideas. "Social media is modifying the ways we communicate and is providing marketers with interactive means to effectively reach consumers. This has given rise to those digital images known as Emoji, which is a trending topic that is shaping our lives and sculpting its way to related social sciences.

Many businesses have been employing emoji in their communication messages, yet little research was conducted in this area. This research will build new insights and will investigate the role of emoji in influencing behaviors in terms of engagement, satisfaction, loyalty, and perception.

Abductive approach to theory was used. Secondary data was collected to explore and explain the concept of online marketing psychology using emoji language. The idea is then tested via survey, to modify the existing theory, and to generate a new idea regarding banks via interview as well.

Research questions investigated the use of emoji in online communication as an effective way to engage consumers, whether emoji lead to better customer satisfaction and loyalty, and how serious organizations can benefit from employing them to break the perceived "coldness".

Results approved the effectiveness of emoji use in marketing, and they're no longer limited to "modern" businesses, rather they're starting to encompass almost all businesses in different industries. The research ends with a set of recommendations that'll guide businesses through this trend."
\end{abstract}

Keywords: Emoji, marketing, social media, satisfaction, loyalty, engagement, banking.

\section{Introduction}

Marketers are not psychologists though they influence their audience through the utilization of psychology and in order to create tempting products to them. Understanding psychology allows marketers to have a better understanding about their audiences' needs and the way they'll react to communication messages (Webster, 1749).

With the booming of technological and mobile devices, mobile firms are seeking new approaches to reach their customers who are attached to their mobiles. Remote communication gives us immediate fulfillment but it lacks face-to-face interaction and thus, lack of body language such as: gestures and eye movement. Such lack of interaction may jeopardize the quality of the message and may result in misinterpretations to the message. Online emojis come handy in reflecting the right feelings intended and minimize misinterpretation by the receiver.

"Emoji are symbolic representations of facial features, nature, body actions, animals, ideas, places, and objects used to add clarification to and reinforce a message between sender and receiver (Takashi, 2016)." Emojis are now considered a universal language that is predicted to be more powerful than words alone. With the popularity of online communication, emojis are now 
considered an effective tool of interaction that adds emotions to a written communication such as irony, joy, and sadness, thus clarifying message intentions and establishing a sense of meaning and acquaintance.

Nowadays, $90 \%$ of people globally utilize emojis in their online interactions, sixty-five percent responded that they "associated to or appreciated them" (Oliveira, 2018). "As marketers and analysts observe the changing consumer environment and the way they communicate, research on how emoji are affecting customer satisfaction, brand connection, and purchase decisions is increasing.

The purpose of this research is to investigate more about this new trend and how it started. It will also examine the different roles of emoji in online advertising, and the psychology behind them. This will clarify how they can affect customer satisfaction, loyalty and behavior. The research then aims at finding out how the banking sector in Lebanon is responding to this trend and how customers are perceiving them."

Research questions:

Is using emojis in online interaction considered an efficient tool to engage audiences?

Will using emojis lead to improved customer-satisfaction \& retention?

How will

How can thoughtful firms take advantage of utilizing emojis and overcome the seeming "emotionlessness"?

Hypotheses

H1: Emojis greatly influence satisfaction, behavior and retention.

$\mathrm{H} 2$ : Emojis assist in maintaining and improving the financial institutions' serious appearance.

H3: Emojis are thought of as a successful tool to push engagement.

\section{Literature review}

It started with a smile :)

To begin with, emoticons are facial expressions established utilizing punctuations. In 1980s Scott Fahlman, a scientist in the computer field who noticed that communication among staff on electronic bulletin boards was going twisted (Steinmetz, 2014). To solve this, he suggested the following: to show humor and/or irony in a communication, insert the textual message with a smiley face through the applying of colon, dash and parentheses ":-) ". Shortly after that, a widespread assortment of emoticons were established including the following:

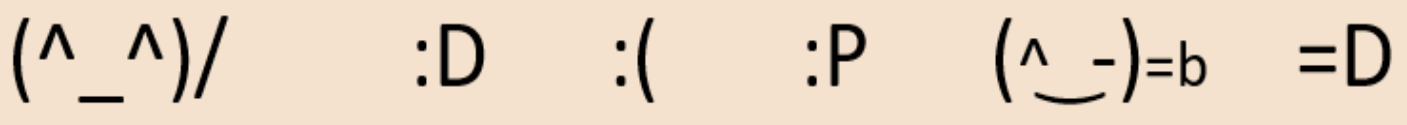

Such emojis dispensed on a wide scale covering the gap missing from the visual cues of personal communication. According to Computational linguist Tyler Schnoebelen, "text messages without emoticons become sort of flat, depleted and dry in terms of those cues that we can use to show exactly what we mean (Steinmetz, 2014)."

In 1999, a Japanese interface designer established the initial assembly of emojis that counted for 176. Soon afterwards, Japanese mobile firms started developing their own individual ones and received patent rights. However, not all versions of new emojis developed by the Japanese firms were compatible with mobile phones. Then, this issue was resolved in 2007 soon a Google 
team requested that Unicode Consortium ${ }^{1}$ form criterions that unifies emojis across platforms.. "Unicode 5.2 included 114 emojis (Walker, 2019)."

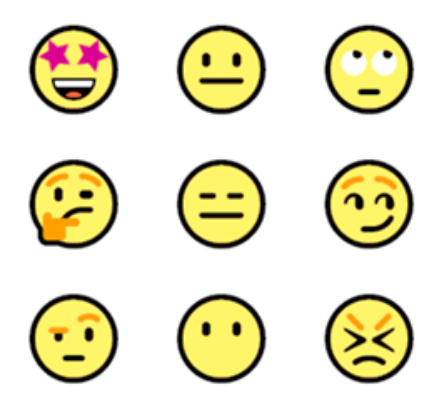

Figure 1. Emoji

Source: Author's own research contribution.

Apple introduced the first emoji keyboard into their smartphones in 2008, and added 608 emoji by 2010. Three years later, Apple was followed by Android.

An emoji may mean different things based on how people interpret it. As a result, companies today find a need for experts in this field to communicate with their audiences and have knowledge of how to use emojis to avoid misinterpretations of messages and to reflect the intended meanings by customers.

Emoji were further upgraded to 'Bitmoji': a customized cartoon avatar that represents a person's own emoji. Today and more than ever, our real and virtual lives are being linked, which brings the need to express our true self digitally in the virtual world that connects us with real people and affects our regular life. 'Bitmoji' allows a person to create his/her own avatar, which becomes an online version of who they are. In other words, they will have their own digital character that represents them when connecting digitally with others (Krueger, 2019).

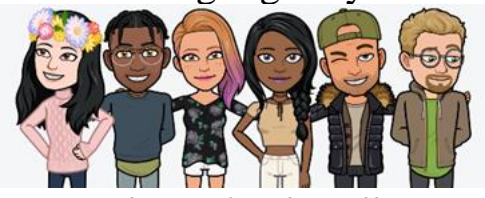

Figure 2. Bitmoji

Psychological aspect of emoji:

Source: www.bitmoji.com.

'People' is the single common aspect between businesses. Where there are people, there is psychology. Emoji are considered a psychological tool that triggers emotions (Seiter, 2015). When we communicate face to face we automatically mimic each other's facial expressions, tones, and movement and bond (Jean Decety, 2011). This is why face-to-face communication is the richest communication since it transfers all these feelings, however, before emojis online communication lacked all of these expressions and thus was emotionless.

"A study done by (Churches, Thiessen, Nicholls, \& Kohler, 2014), has proved that the brain reacts similarly when viewing a digital smiley face as when they view an actual person smiling. And this reaction isn't innate; rather, it was developed cumulatively after the emergence of emoji. Before, there was no reason for an emoticon to trigger face recognition areas of the cortex. But now it does since we've learned that these punctuations symbolize a face. This neural response is

${ }^{1}$ A standard for encoding characters with universal acceptance to ensure compatibility across platforms. 
culturally-created (Hakami, 2017). Thus, emoji could have a vital impact on people psychologically and emotionally."

"Moreover, humans can recall $10 \%$ of what they hear and $20 \%$ of what they read, but they will remember $80 \%$ of what they see and do (Pillars, 2015). Thus the more the marketing message contains visual triggers, the more likely it'll be remembered and will have a long-term impact."

Objectives of using emoji in online ads:

PICBE |

Emoji give the business a human-like personality and identity and convey accurate human emotions that are perceived as real, honest, and approachable (YEC, 2017).

Emoji increase conversations on social media thus boosting engagement. On Twitter: tweets that included emoji witnessed $25.4 \%$ more engagement. On Facebook: emoji increased like rates by $57 \%$, comment and share rates by $33 \%$ (Kim, 2018) (Decker, 2018). On Instagram, 56.5\% of accounts include emoji in their comments (Kmiećkowiak, 2017). Adding emoji to the subject part of emails increase open rates by $56 \%$ (Kennedy, 2017). Also push notifications had an $85 \%$ increase in open rate when they included emoji (Fleit, 2017).

Emoji express what words cannot: for example, if someone texted you saying: "I'm looking forward to it" vs. "I'm looking forward to it!" vs. "I'm looking forward to it ^ُ". You experience a little bit of different feelings with the text right? Although the statement did not change, the conveyed feelings did (Decker, 2018).

Social media is made to be engaging and entertaining. Even businesses that are more traditional can take advantage of it to leverage a more relaxed and friendly voice that customers will appreciate (YEC, 2017).

Research shows that $72 \%$ of 18 to 25 year olds prefer using emoji to express their feelings. $68 \%$ of US adults are on Facebook (Cooper, 2018) where they are exposed to reaction buttons, stickers and gifs. Thus, it is valuable to incorporate emoji to nurture positive association with a product or brand (Day, 2019).

They enhance the user experience (UX): site speed and ease of navigation are some of the terms of gauging a website's quality for UX. If you visit Google, type in the pizza emoji " 2 " and add "near me" Google will give you results of nearby pizza restaurants. It is both fast and accurate thus enhancing the UX (Sauciuc, 2018)

\section{Emoji in ad campaigns}

CNN created an emoji for each presidential candidate of the US 2016 elections, so people can show support for their favorite candidate by tweeting or texting their visage."

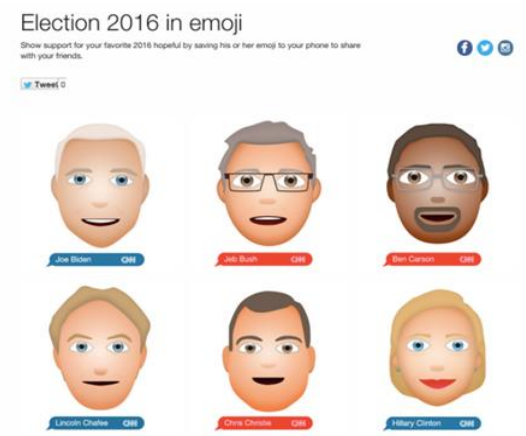

Figure 3. US election

Source: www.buffer.com/resources/emojis/. 
"The 'People for the Ethical Treatment of Animals (PETA)' created a short video using emoji to create awareness on what animals endure for fashion purposes (Seiter, 2015).

McDonald's created a billboard using only emoji as a promotion for their restaurants in the UK.

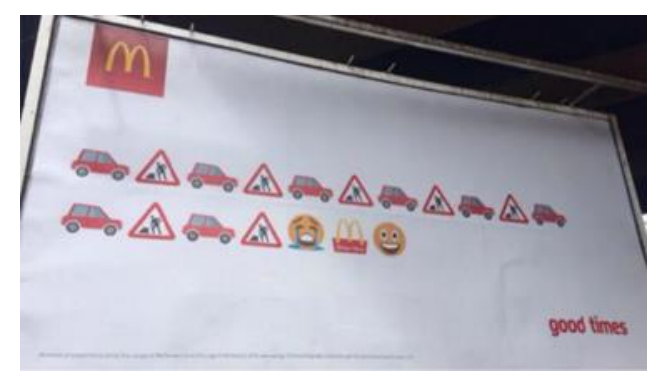

PICBE |

Facebook, Linkedin, and other apps added reaction buttons allowing users to react as they feel about a post:"

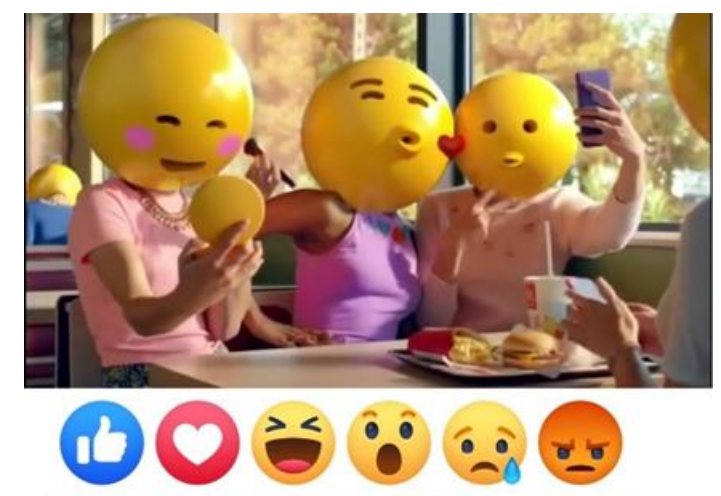

Figure 5. Fb Reaction buttons

Source: www.facebook.com.

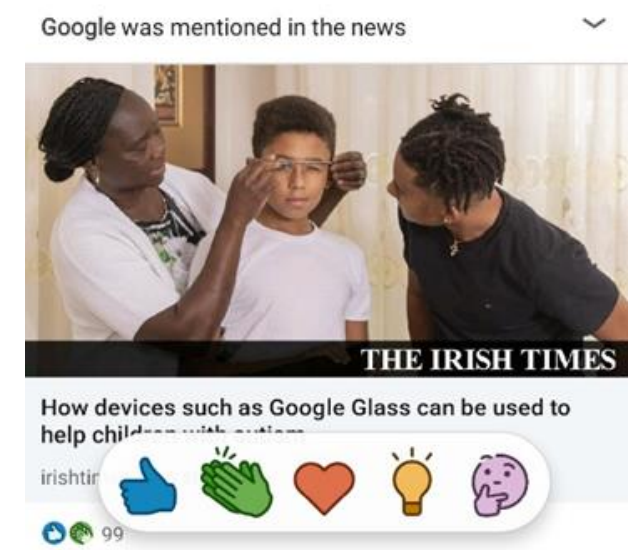

Figure 6. LinkedIn reaction buttons

Source: www.linkedin.com. 
Emoji and customer satisfaction, loyalty, and behavior:

"A study found that customers felt more warmth when dealing with customer service employees who used emoji, and thus felt more satisfied with the business (Li et al., 2019). When companies establish an online presence, they must demonstrate a human voice in their conversations with customers. Interactions must be perceived as candid, collaborative, and human. Emoji add these three traits. Customer engagement will increase, and they'll feel more connected to the brand and eventually become loyal. The study showed that customers felt that emoji in promotional messages reinforce a message's intensity and aid in understanding it (Luangrath et al., 2016).

The way businesses communicate with their consumers has more impact on their relationship and how customers evaluate the brand than any other strategy or success. And compared to traditional communication tools, new tools are considered more expressive, friendly, relaxed, and easier to understand. (Arya et al., 2018).

A research conducted in Penn University demonstrated that using emoji led to a $78 \%$ increase in customer satisfaction relative to basic text (Ember, 2019). When businesses engage with consumers they make them feel good. And people will remember the brand. Sometimes all it takes to please customers is a pair of words and an emoji! (White, 2018)."

\section{Methodology}

Primary quantitative data was collected via a clearly constructed survey. Respondents' options were Yes or No, selecting among alternatives, and ranking on a scale. Data was distributed across three levels: Starting with demographic. Followed by emoji perception by customers in their everyday lives and in business communication. The third is about emoji used by banks in Lebanon. The SPSS program was used to test correlation between variables. Data is analyzed using graphical representations.

Primary qualitative data was obtained via interview conducted with Bank of Beirut's marketing department team. Content and narrative analysis were used. Their stories and experiences increased the research's scope and insights and answered research questions.

In the analysis part, results were interpreted to investigate if the incorporation of emojis by companies in their online interaction with their audience is effective and beneficial.

"Dependent variables: satisfaction, loyalty, behavior, level of engagement and perception of image. Independent variable: emoji. To test how the use of emoji by businesses online can affect all the other factors."

Non-probability sampling was used. To ensure accurate results and convenience, I targeted the online population. And because these people are confronted with online ads. The sample selected comprised Lebanese people between 18 and 65. The survey was distributed on Facebook, WhatsApp, Instagram and LinkedIn also via email link. It generated 110 responses.

\section{Results and discussions}

Not all the collected data was included, only the ones necessary for the purpose of this research. The first two questions were identification questions that introduced respondents: the aim was to find out how gender and age relates with emoji perception. 
Table 1. Gender*like cross-tabulation

\begin{tabular}{|ll|r|r|r|}
\hline \multirow{2}{*}{} & & \multicolumn{2}{|c|}{ Do you like emoji } & \multicolumn{1}{c|}{ Total } \\
\cline { 3 - 4 } & \multicolumn{2}{|c|}{ Yes } & No & \\
\hline \multirow{2}{*}{ gender } & Male & 41 & 2 & 43 \\
Total & Female & 65 & 1 & 66 \\
\hline
\end{tabular}

Source: Authors' own research.

PICBE |

This table is a cross tabulation of "emoji" and "gender" variables. $60 \%$ of respondents were women reflecting that women more than men like emojis. Thus, out of 106 respondents who said yes they like emojis, 65 were women, while 41 were men. Examining previous research identified that females are more responsive to emoji than men (Andral and Larroque, 2016).

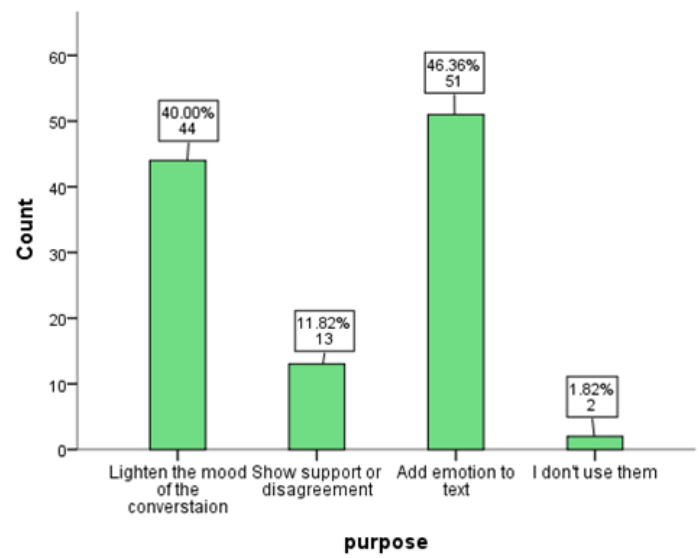

Figure 3. Reasons of using emoji

Source: Author's own research.

" $46.36 \%$ use emoji to add emotion to the text, $40 \%$ said they lighten the mood of the conversation, $11.8 \%$ use them to show support or disagreement, while $1.8 \%$ said they did not use them (those who did not like them)."

Table 2. Age*emoji cross-tabulation

\begin{tabular}{|c|c|c|c|c|}
\hline & \multicolumn{2}{|c|}{ Do you like emoji } & \multirow[t]{2}{*}{ Total } \\
\hline & & Yes & No & \\
\hline \multirow{6}{*}{ age } & $<18$ & 3 & 0 & 3 \\
\hline & $18-24$ & 30 & 0 & 30 \\
\hline & $25-34$ & 41 & 0 & 41 \\
\hline & $35-44$ & 16 & 2 & 18 \\
\hline & $45-54$ & 10 & 1 & 11 \\
\hline & $55-64$ & 6 & 0 & 6 \\
\hline Tota & & 106 & 3 & 109 \\
\hline
\end{tabular}

Source: Author's own research.

"We can notice that emoji are pretty much appreciated among different age groups. 6 people in the age group of 55 to 64 said yes. Perhaps this exposure is making them change their perceptions and blend in with the younger groups.

Table 3. Brands using emoji and satisfaction levels 


\begin{tabular}{|c|r|r|r|r|r|}
\hline \multirow{2}{*}{$\begin{array}{c}\text { What do you think about } \\
\text { brands using emoji }\end{array}$} & \multicolumn{6}{|c|}{ satisfaction } \\
\cline { 2 - 7 } & $\begin{array}{c}\text { Very } \\
\text { unsatisfied }\end{array}$ & Unsatisfied & Neutral & Satisfied & $\begin{array}{c}\text { Very } \\
\text { satisfied }\end{array}$ \\
\hline Fun/Funny & 1 & 0 & 10 & 19 & 15 \\
\hline Trendy & 0 & 0 & 12 & 21 & 14 \\
\hline Somewhat unprofessional & 2 & 4 & 4 & 1 & 0 \\
\hline Cheesy/low-end & 1 & 2 & 0 & 0 & 1 \\
\hline Total & 4 & 6 & 26 & 41 & 30 \\
\hline
\end{tabular}

PICBE |

Table 4. Liking emoji \& Criteria

\begin{tabular}{|c|r|r|r|}
\hline \multirow{2}{*}{$\begin{array}{c}\text { Do you like } \\
\text { emoji }\end{array}$} & \multicolumn{2}{|c|}{ criteria } & \multicolumn{1}{c|}{ Total } \\
\cline { 2 - 3 } & Yes & \multicolumn{1}{|c|}{ No } & \\
\hline Yes & 77 & 29 & 106 \\
No & 0 & 3 & 3 \\
Total & 77 & 32 & 109 \\
\hline
\end{tabular}

Source: Author's own research.

It appears from the above tables that people who consider emoji use by brands as fun/funny and trendy are those who are satisfied with dealing with those brands. 40 people were satisfied, 29 were very satisfied (delighted) and only 1 was very unsatisfied. In total 71 people were positively satisfied while 10 were not. This tips the scale in favor of brands using emoji.

Obviously, those who did not like emoji and did not use them perceived them negatively when used by brands but the higher percentage goes in favor of using them.

$72.64 \%$ of people who like emoji consider them as criteria to pick one brand over another. People who did not like emoji didn't think of it as criteria to choose between brands. Thus people are more willing to choose brands that use emoji over those that do not. Implying that they are satisfied with them. And the literature proved that satisfied customers are happy customers and thus more loyal and have a positive behavior toward the business."

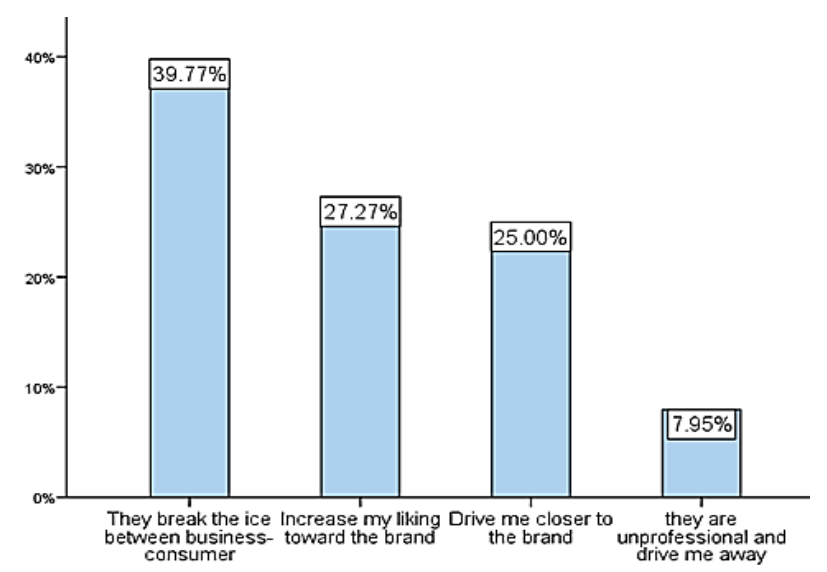

Figure 4. Reasons behind emoji as criteria

Source: Author's own research. 
"39.77\% said emoji break the ice between business-consumer. $27.27 \%$ said emoji made them like the brand more while $25 \%$ said emoji drive them closer to the brand. If emoji are driving consumers closer to the brand, increasing their liking towards it, and breaking the ice between the two parties, consumers will be more loyal.

The $6^{\text {th }}$ question presented pictures of two posts by two companies. One post included emoji in the caption while the other did not. Respondents were asked to choose the picture they thought was more attractive. "

PICBE |

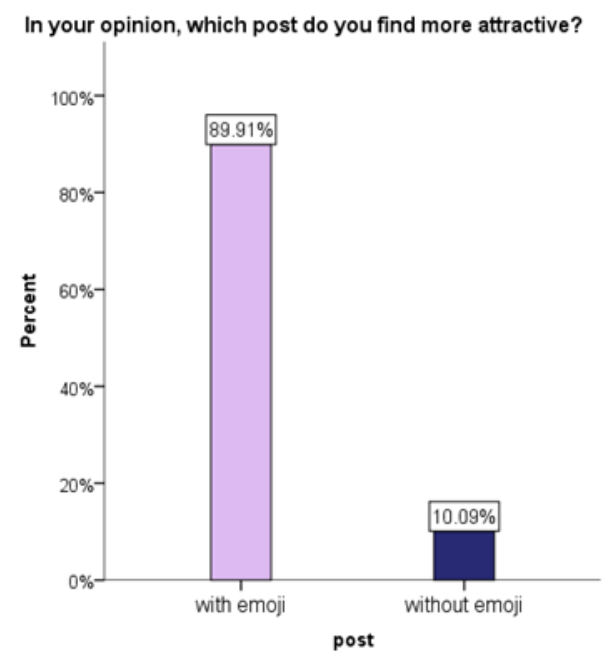

Figure 5. Posts by companies

Source: Author's own research.

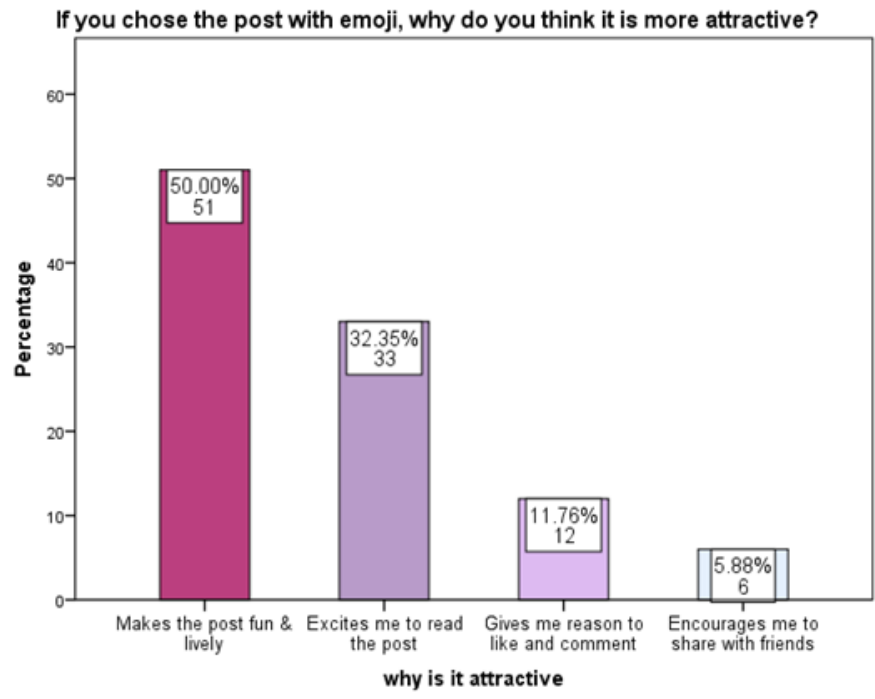

Figure 6. Reasons for choosing post with emoji

Source: Author's own research.

"For $89.91 \%$ of respondents, the post that included emoji was more attractive and for $10.09 \%$ the other one was better. Reasoning: $50 \%$ of respondents said that it made the post more fun and lively, $32.35 \%$ said it excited them to read the post, $11.76 \%$ answered that it gave them reason to like and comment (engage), and $5.88 \%$ said that it encouraged them to share with friends. 
This tells us that emoji use by brands drives engagement and encourages customers to promote positive electronic word-of-mouth.

The last part was specific to banking. Respondents were asked if they think banks can use emoji in online ads like any other business."

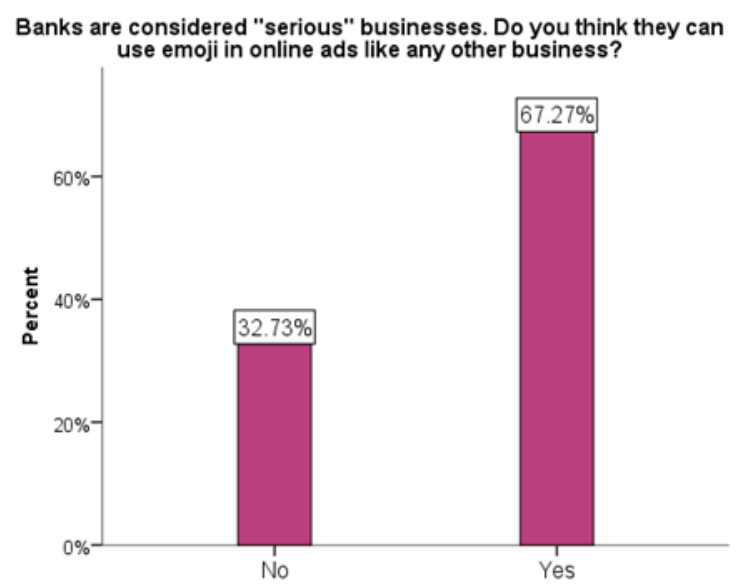

Figure 7. Emoji by banks

Source: Author's own research.

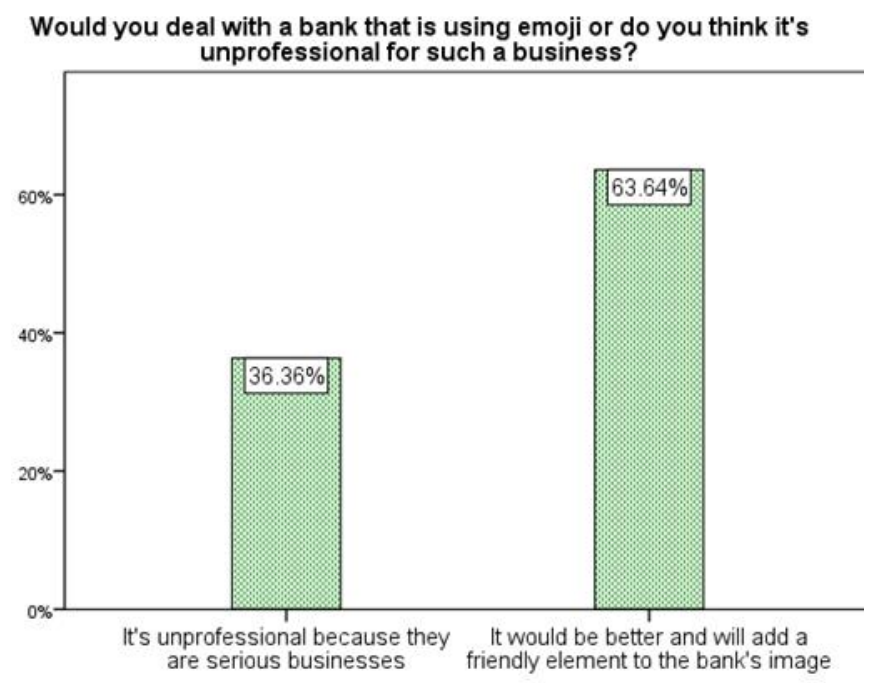

Figure 8. Dealing with bank using emoji

Source: Author's own research.

"More than half of the respondents (67.27\%) answered yes while 32.72\% answered no. This signifies that people are prone to accept emoji in the banking sector and thus serious businesses in general. Those who answered yes to this question were almost the same when asked if they would deal with a bank using emoji. 63.64\% thought it would be better and would add a friendly element to the bank's image. While $36.36 \%$ (those who answered no to the previous question) said it's unprofessional for a serious business.

After that, I presented a post by BOB that included emoji and asked respondents if they think other banks should follow their lead." 


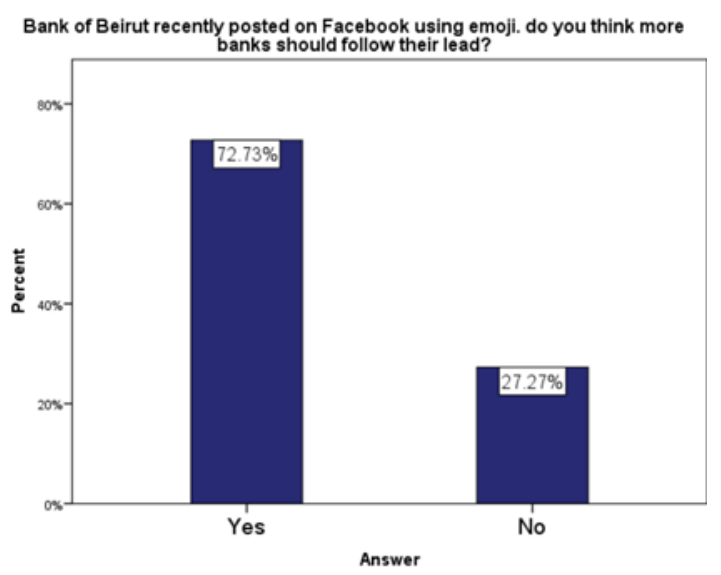

PICBE |

Figure 9. BOB post

Source: Author's own research.

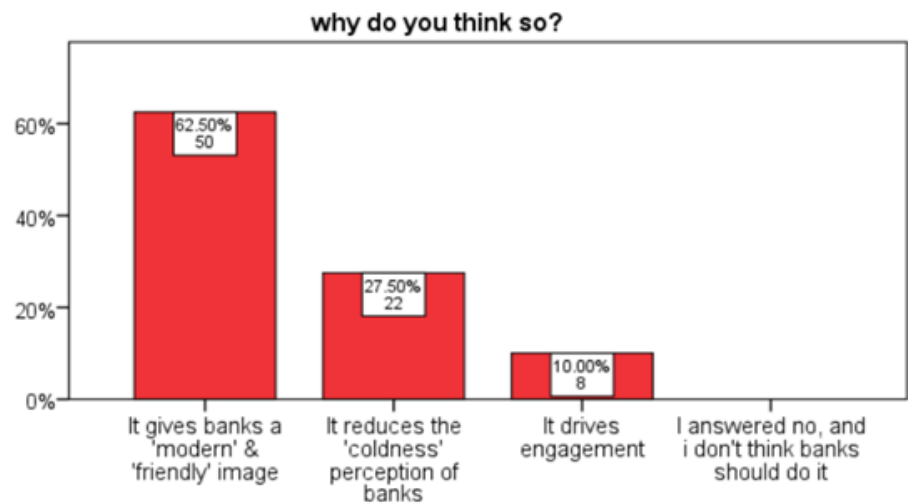

Figure 10. Why banks should use emoji

Source: Author's own research.

" $72.73 \%$ said yes and the remaining $27.27 \%$ said no. The reasoning for $62.5 \%$ of them was that it gives banks a modern and friendly image. For $27.5 \%$ emoji reduce the 'coldness' perception of banks. The other $10 \%$ answered that it drives engagement."

\section{Analysis:}

"People use emoji because they are enjoyable and a worthy addition to communication methods. Survey data showed that $46.36 \%$ of participants use emoji 'to add emotion to text': people are using emoji to convey the right feelings and add the desired emotion to the text, to avoid any confusion with the receiver. Nowadays, normal words scattered in a text are not sufficient to make the converser understand exactly what you're trying to say or feelings you're intending to convey.

Brands using emoji have understood the importance of emotions in building customer loyalty. Savvy marketers add an emotional element to their online ads to influence consumers' behavior.

In the survey respondents answered how they would feel about purchasing or receiving an emoji product. The objective was to check if emoji triggered an emotion or a cognition. 
Table 5. Emoji product \& gender cross-tabulation

\begin{tabular}{|l|l|r|r|r|}
\hline \multirow{2}{*}{$\begin{array}{c}\text { How would you feel about } \\
\text { buying/receiving emoji products? }\end{array}$} & \multicolumn{2}{|c|}{ gender } & \multirow{2}{*}{ Total } \\
\cline { 2 - 4 } & $\begin{array}{l}\text { Reminds me of a person, a } \\
\text { feeling, a conversation, or a } \\
\text { good moment }\end{array}$ & 18 & 26 & \multirow{2}{*}{ Female } \\
\cline { 2 - 5 } & $\begin{array}{l}\text { It's trendy to have an emoji } \\
\text { product }\end{array}$ & 3 & 12 & $\mathbf{1 5}$ \\
\cline { 2 - 5 } & $\begin{array}{l}\text { Emoji products are original } \\
\text { and fun }\end{array}$ & 7 & 15 & $\mathbf{2 2}$ \\
\cline { 2 - 5 } & Not interested & 16 & 13 & $\mathbf{2 9}$ \\
\hline Total & \multicolumn{44}{|c|}{} & $\mathbf{6 6}$ & $\mathbf{1 1 0}$ \\
\hline
\end{tabular}

PICBE | 86

The main reason that would make respondents interested in emoji products is that it acts as a reminder; it reminds them of a person, a feeling, a conversation or a good moment they shared with someone." According to the Memorization Theory explained by Neil (Limited, 2019), using emoji in ads "leads to exposing the brand image repeatedly (Hussain, 2017). And repetition is essential for memorizing which leads to learning which further leads to recognition. Thus when brands use emoji, they create an image for themselves that's associated with a more visual representation that gets stuck in consumers' minds. Whenever they see a certain emoji, an image of a certain brand pops up in their heads."

\section{"Brand image perception}

Businesses use emoji believing that they will make them seem more friendly and approachable (Grigonis, 2019). This can be linked to the third part of the survey; previous graphs indicated that emoji do not hurt the serious image of traditional businesses, rather they tend to improve their image by adding that friendly element.

The perception that serious businesses should remain traditional is clearly changing. With more people accepting this trend in the banking sector $(67.27 \%$ ) while only $32.73 \%$ did not; out of which $22.2 \%$ changed their minds after seeing the BOB post as presented in the table below.

Table 6. Brands using emoji with BOB post

\begin{tabular}{|c|r|r|r|}
\hline $\begin{array}{l}\text { Do you think banks can } \\
\text { use emoji in online ads like } \\
\text { any other business? }\end{array}$ & \multicolumn{2}{|c|}{$\begin{array}{c}\text { Do you think more banks should } \\
\text { follow BOB's lead? }\end{array}$} & \multirow{2}{*}{ Total } \\
\cline { 2 - 4 } & Yes & No & \\
\hline Yes & 72 & 2 & 74 \\
Total & 8 & 28 & 36 \\
& 80 & 30 & 110 \\
\hline
\end{tabular}

Source: Author's own research.

Finally, companies' existence revolves around making profits, so in order to increase their profits they should practice innovation and adaptation to emerging trends. According to the survey $43.12 \%$ of respondents believe that emoji are trendy, hence, by adopting this new trend companies are taking part of this "innovation practice".

This analysis leads to accepting $\mathrm{H} 1, \mathrm{H} 2$, and $\mathrm{H} 3$ that state, respectively: Emoji positively affect customer satisfaction and behavior. 
Emoji help maintain and improve the bank's serious image.

Emoji are considered an effective way in today's online communication and engagement."

\section{Interview Analysis:}

The interview revolved around the following:

The bank's online marketing strategy

Purpose of using emoji in their online communications

PICBE |

Consumer category they were targeting with emoji

Customer engagement and changes in behavior

Answers revealed that, firstly, what differentiates BOB is that their marketing strategy is done in-house: "An outside-agency wouldn't have the guts to add emoji to online communications". They use emoji because it's something that everyone can relate to, it's better than posting a man or woman's face. And it also drives engagement. They noticed that posts that included emoji reached $5 \mathrm{k}+$ likes while it was limited to the hundreds with posts that did not. They noted that emoji add 'tone' and clarity to the communicated message, people are finding it easier and faster to communicate using emoji, and the more visually appealing the post is the better it is to catch their attention. Emoji removed the barrier between people and bankers and replaced formality with friendliness. Which proves the hypothesis even further that emoji breaks the coldness perception of banks and drive up engagement.

Using emoji in online posts has encouraged people to reply with emoji or comment plus emoji. Their target audience was "everyone!" but depending on the platform: on Facebook they're targeting people in their mid-thirties, 40s and older. On Instagram they target younger people.

They also created "DiGi BoB" like a Bitmoji character that people refer to every time they need a banking tip. And it's not rigid, it's not banking, it gives the bank a friendly human representation.

The bank is also using emoji in handling people's requests and complaints. They received positive commentary, people never expected a bank to reply this way. They loved it: increased satisfaction.

However, using emoji in the phone application is out of perspective because it's too corporate. On social media they're social, on more serious platforms they're corporate and this is how they balance it to preserve professionalism. However, future wise they might incorporate icons that act as triggers, like a 'cash bag' that will transcript making deposits.

$\mathrm{BOB}$ gave banking a new perspective that is easy, friendly, and overall professional. They succeeded in establishing a balance between corporate and modern. They were able to increase customer engagement and noticed positive behavior. They are proof to other banks in Lebanon that this trend doesn't harm the bank's image when done appropriately."

\section{Conclusion}

Emoji are now a universal language that can tear down language impediments. They're dynamic; always updated to reflect new trends and social changes, and are being used by organizations to create awareness and promote causes and movements.

Emoji have the power to convey some communicative force that might otherwise remain obscure from the plain positioning of words (team, 2015).

The simplest way for businesses to add personality to their social presence is the use of emoji. This pop of color will add a sentiment to a post. They're perfect for giving the brand a 
humanized identity. Appropriately adding emoji to an online marketing message will support and reinforce that message.

Traditional businesses can no longer ignore this trend. The world is changing, and so are people. Emoji are pretty much everywhere and businesses should at least consider integrating them in their online campaigns.

The use of emoji is only increasing in the digital marketing area, but only a few studies have been conducted to gauge its effectiveness, hence the decision to realize this research. The survey's outcomes showed that people are leaning more toward the use of emoji in online ads.

This research examined the use of emoji by businesses online by comparing their use between modern, fun organizations and traditional, serious organizations to come up with the hoped for result that traditional businesses will not harm their image by using emoji in their online ads, and that emoji are a powerful communication tool to be used when reaching consumers, no matter the type of business."

\section{Study limitations}

First, non-random sampling was used because of time constraints and the inability to reach an appropriate sample using a non-probability technique. Second, only a few researches existed in the area. That's why I tried to fill a missing gap in prior theories and make room for further research and investigation. Third, surveys are self-reported, some respondents may not have taken it seriously and thus answered randomly or skipped questions. This may make the results not completely valid. Finally, the sample was not properly balanced in terms of age and gender."

\section{Recommendations}

Don't overuse emoji: emoji overuse might become chaotic. Instead of simplifying the message, it might make it impossible to understand (McGrath, 2018).

Know your target audience: marketers have to understand how their audience reacts to emoji. Studying the market helps to find out how people use and perceive them, and how age, gender and location affect it (Comcowich, 2019).

Make them relevant: if emoji are not related to the campaign or brand, they shouldn't be used. Marketers should also make them relevant for different countries. Cultural and geographical differences affect emoji frequency of use and perceived meanings.

Avoid manipulation: it's never a good idea to play on people's feelings. Using emoji should be fun and sincere like talking to a friend. Careful implementation leads to better outcomes.

For banks, BOB serves as a great example that using emoji is an effective way to communicate with customers online. Other banks should follow their lead and incorporate emoji into their online ads to improve their image and drive engagement.

Emoji have become an integral mean of communication, so emoji marketing must also be an integral part of the way brands communicate their messages. Marketers should not let their personal opinions come in the way of using emoji. They should study the market and let the data decide."

\section{References}

Andral, M., \& Larroque, A. (2016). The emojis consumer perception in the online advertising. Halmstad, Sweden: Halmstad University.

Arya, V., Sethi, D., \& Verma, H. (2018). Are emojis fascinating brand value more than textual language? Mediating role of. Corporate Communications, 24. 
Bitmoji (2019). Retrieved from https://www.bitmoji.com/.

Churches, O., Thiessen, M., Nicholls, M., \& Kohler, M. (2014, January). Emoticons in mind: An event-related potential study. Social neuroscience.

CNN (2016). Election 2016 in emoji. CNN.

Comcowich, W. (2019). glean.info. Retrieved July 28, 2019, from https://glean.info/best-employemoji-pr-marketing-communications/.

Cooper, P. (2018). hootsuite. Retrieved July 27, 2019, from https://blog.hootsuite.com/facebookstatistics/.

Cruelty beyoond words (2014). [Motion Picture]. USA.

Day, C. (2019). agora pulse. Retrieved July 27, 2019, from https://www.agorapulse.com/blog/ should-your-agency-use-emojis-in-social-media-really.

Decker, A. (2018). HubSpot. Retrieved July 24, 2019, from https://blog.hubspot.com/marketing/ emojis.

Ember (2019). ember. Retrieved July 28, 2019, from https://www.emberrealresults.com/news/ emojis-in-customer-service-cheeky-or-charming/.

Facebook (2017). Facebook. Retrieved July 28, 2019, from http://www.facebook.com.

Fleit, B. (2017). HubSpot. Retrieved July 25, 2019, from https://blog.hubspot.com/marketing/emoji -push-notifications?_ga=2.68446865.1080538756.1539600340-413763328.1527791872.

Grigonis, H. K. (2019). digital trends. Retrieved August 17, 2019, from https://www.digitaltrends .com/social-media/emoji-trend-report-2019/.

Hakami, S. A. (2017). The Importance of Understanding Emoji. UK.

Hussain, I. (2017). Pedagogical Implications of VARK Model of Learning. Journal of Literature, Languages and Linguistics , 38 (2422-8435), 5.

Jean Decety, W. I. (2011). The Social Neuroscience of Empathy (2nd edition ed.). MIT Press.

Kennedy, L. (2017). SendPulse. Retrieved July 25, 2019, from https://sendpulse.com/blog/emojiin-email-subject-lines.

Kim, L. (2018). WordStream. Retrieved July 25, 2019, from https://www.wordstream.com/blog/ ws/2015/11/19/twitter-emoji.

Kmieckowiak, T. (2017). Quintly. Retrieved July 25, 2019, from https://www.quintly.com/blog/ instagram-emoji-study.

Krueger, A. (2019). Forbes. Retrieved July 24, 2019, from https://www.forbes.com/sites/aly sonkrueger/2016/03/24/the-deeper-meaning-behind-bitmojis-why-we-all-love-them-somuch/\#60dfbca04a43.

Limited, V. L. (2019). VARK. Retrieved August 17, 2019, from http://vark-learn.com/introductionto-vark/the-vark-modalities/.

LinkedIn (2019). LinkedIn. Retrieved July 28, 2019, from https://www.linkedin.com/.

Luangrath, A. W., Peck, J., \& Barger, V. A. (2016). Textual paralanguage and its implications for marketing communications. Consumer Psychology, 27(1), 10.

McGrath, L. (2018). Rebrandly. Retrieved July 26, 2019, from https://blog.rebrandly.com/emojimarketing/.

Oliveira, J. (2018, March 23). Appsol. Retrieved from https://appsolinfosystems.com/ app_wps/blog/2018/03/23/emoji-the-new-global-language/.

Pillars, W. (2015). Visual Note-Taking for Educators: A Teacher's Guide to Student Creativity. W. W. Norton \& Company.

Sauciuc, A. (2018). CognitiveSEO. Retrieved July 27, 2019, from https://cognitiveseo.com/blog/ 20067/emoji-seo-strategy/\#3.

DOI: $10.2478 /$ picbe-2021-0008, pp. 75-90, ISSN 2558-9652 |

Proceedings of the $15^{\text {th }}$ International Conference on Business Excellence 2021 
Seiter, C. (2015). The psychology of emojis. Noudettu, 4, 2020.

Seiter, C. (2020, June 30). This is Your Brain on Emojis. Here's How to Use Them in Your Marketing. Retrieved from https://buffer.com/resources/emojis/.

Steinmetz, K. (2014). Time. Retrieved July 23, 2019, from https://time.com/3341244/emoticonbirthday/.

Takashi, T. (2016). Computational and Cognitive Approaches to Narratology. IGI Global.

team, E. r. (2015). 2015 Emoji Report. Google.

PICBE |

Walker, T. (2019). A Medium Corporation. Retrieved July 23, 2019, from https://medium.com/ @ heytory/emojis-the-complete-history-6dc81a330144.

Webster, M. (1749). Retrieved from https://www.merriam-webster.com/dictionary/psychology\#h1.

White, J. (2018). Social marketing solutions. Retrieved July 28, 2019, from https://social marketingsolutions.com/2018/12/24/learn-how-coffee-mate-wins-customer-loyalty-withjust-two-words-and-an-emoji/.

YEC (2017). Small business trends. Retrieved July 24, 2019, from https://smallbiztrends.com/ 2017/05/should-businesses-use-emojis-on-social-media.html”. 